\title{
Typology of Houses for Fishermen Disaster Response to Fishermen's Settlements in the Rangas Distrrict of Majene, West Sulawesi
}

\author{
Sutriani $^{1}$, Muhammad Harum ${ }^{2}$ \\ 1. Faculty of Sipil Engineering, Sulawesi Barat University \\ 2. Faculty of Sipil Engineering, Sulawesi Barat University \\ *e-mail: Sutrianishafa@gmail.com,Harum.muhammad@yahoo.com
}

\begin{abstract}
Article Title. The high annual percentage of the population has an impact on the level of population density. The increase in population affects the level of need for shelter that creates new settlement groups. The need for each year has increased with the creation of residential space groups that have made coastal space areas so fast that sometimes ignoring the aspects of security, protection and government regulations that only want space to be able to build a house as a place where they live. The study of the problem in this study is how the typology of houses that are responsive to disasters in the fishing settlement space in Rangas, Majene Regency, West Sulawesi with the approach to the use of space in relation to the typology of the house and the factors that influence. The method used is descriptive qualitative by classifying home typology groups based on a matrix grouping by analyzing factors that are considered influential. The results of this study will be seen by comparing the various typologies of the original form of the fishermen's house and the process of its formation in the settlement space pattern by looking at the effect factors. Then determine several houses that are responsive and prone to disasters. Recommended recommendations from this research will result in proposals for the shape and model of disaster-responsive fishing houses with structural specifications, material use, and appropriate spatial placement in the Fisherman Settlements in Rangas, Majene Regency.
\end{abstract}

Keywords: Typology, disaster response, fishermen's house.

\begin{abstract}
Abstrak
Tingginya persentase tahunan jumlah penduduk berdampak terhadap tingkat kepadatan penduduk. Meningkatnya jumlah penduduk mempengaruhi besarnya tingkat kebutuhan akan tempat tinggal yang menciptakan kelompok permukiman baru. Kebutuhan tiap tahun semakin meningkat dengan terciptanya kelompok ruang permukiman telah menjadikan wilayah ruang pesisir begitu pesat sehingga kadang mengabaikan segi keamanan, perlindungan dan aturan pemerintah yang hanya menginginkan ruang untuk dapat mendirikan rumah sebagai tempat mereka bermukim. Kajian permasalahan dalam penelitian ini adalah bagaimana Tipologi rumah yang tanggap terhadap bencana pada ruang permukiman nelayan di Rangas, Kabupaten Majene, Sulawesi Barat dengan pendekatan pola pemanfaatan ruang kaitannya dengan tipologi rumah serta faktor - faktor yang mempengaruhi. Metode yang digunakan adalah diskriptif kualitatif dengan mengklasifikasikan kelompok Tipologi rumah berdasarkan pengelompokan secara matriks dengan menganalisa faktor yang dianggap berpengaruh. Hasil penelitian ini akan terlihat beberapa perbandingan ragam typology bentuk asli dari rumah nelayan dan proses pembentukannya pada pola ruang permukiman dengan melihat faktor pengaruhnya. Kemudian menentukan beberapa rumah yang tanggap dan rawan terhadap bencana. Rekomendasi usulan dari penelitian ini akan menghasilkan usulan bentuk dan model rumah nelayan yang tanggap bencana dengan spesifikasi struktur, penggunaan material, dan penempatan ruang yang sesuai pada Permukiman Nelayan di Rangas Kabupaten Majene.
\end{abstract}

Kata Kunci: Typologi,tanggap bencana, rumah nelayan. 


\section{Pendahuluan}

Program pemerintah melalui Kementerian Pekerjaan Umum dan Perumahan Rakyat (PUPR) pada periode 2016-2019 mencanangkan adanya program penataan Kawasan Permukiman Nelayan dan Tepi Air di 11 lokasi di Indonesia. Kawasan tersebut diharapkan dapat menjadi contoh untuk pengembangan permukiman nelayan di beberapa wilayah pesisir yang ada di Indonesia, namun hal ini tak cukup jika tanpa mempertimbangkan kondisi wilayah utamanya terhadap kerawanan bencana pada permukiman di kawasan pesisir yang berpotensi menyebabkan timbulnya resiko terjadinya bencana yang dipicu oleh kejadian alam maupun ulah manusia oleh karenanya kebijakan relokasi itu harus dapat mengakomodir isu yang ada dimasyarakat sehingga pengembangan program rumah tanggap bencana dengan kombinasi teknologi akan dapat diterapkan pada beberapa wilayah permukiman khususnya di Indonesia. Teknologi produk Rumah Instan Sederhana Sehat (RISHA) yang telah ditawarkan pemerintah kepada para pengembang menjadi bentuk perhatian pemerintah saat ini, namun masih banyak wilayah pesisir yang belum menerapkan dan belum mengetahuinya adanya, maka dari itu diperlukan peninjauan dibeberapa wilayah perumahan dan permukiman yang dapat menerapkan program tersebut. Di Indonesia merupakan wilayah potensi bencana yang sangat Tinggi ( hazard potency), diantaranya adalah gempa bumi, banjir, letusan gunung api, tanah lonsor, angin ribut, kebakaran hutan dan lahan. Terdapat 2 kelompok potensi bencana, yakni potensi bahaya utama (main hazard) dan potensi bahaya ikutan (collateral hazard) dalam permendagri No.33 Tahun 2006. Terlihat dalam peta potensi bencana gempa, peta potensi bencana tsunami, peta potensi bencana banjir, peta potensi tanah longsor, peta potensi letusan gunung api, menandakan bahwa Indonesia merupakan wilayah meliputi zona zona gempa yang rawan, rawan terhadap banjir, rawan tanah longsor, rawan terhadap letusan gunung api, rawan tsunami dari indikator-indikator ini dapat disimpulkan bahwa Indonesia memiliki potensi bahaya utama (main hazard potency) yang tinggi. Selain itu Indonesia memiliki potensi bahaya ikutan (collateral hazard potency) yang sangat tinggi. Hal ini dapat dilihat dari beberapa indikator misalnya likuifaksi, persentase bangunan yang terbuat dari kayu, kepadatan bangunan, dan kepadatan industri berbahaya. Potensi bahaya ikutan (collateral hazard potency) ini sangat tinggi terutama di daerah perkotaan yang memiliki kepadatan, persentase bangunan kayu (utamanya di daerah pemukiman kumuh perkotaan), dan jumlah industri berbahaya.

Majene merupakan salah satu wilayah pesisir terpanjang di wilayah Sulawesi Barat dengan peruntukan lahan dalam ruang kawasannya ini lebih memungkinkan sebagian besar masyarakatnya bermukim di area pesisir dan pulau. Perkembangan permukiman di area ini semakin pesat, hampir dalam setahun mengalami peningkatan yang cukup signifikan. Tingginya persentase tahunan jumlah penduduk di wilayah ini menjadi patokan dasar dalam melihat tingkat kepadatan penduduk diarea tersebut. Meningkatkatnya jumlah penduduk ini sangat mempengaruhi besarnya tingkat kebutuhan akan tempat tinggal di wilayah tersebut, terbentuknya tempat tinggal ini akan menciptakan beberapa kelompok permukiman baru dengan karakteristiknya masing-masing. Terbentuknya beberapa kelompok permukiman akan berpengaruh terhadap penggunaan lahan yang semakin tahun semakin berkurang sedangkan kebutuhan tiap tahun semakin meningkat. Terciptanya kelompok ruang permukiman telah menjadikan wilayah ruang pesisir begitu pesat, bahkan peraturan akan sempadan ruang pesisir yang seharusnya terbebas dari pemanfaatan ruang kadang sudah tidak diindahkan. Batas sempadan pantai yang semestinya $100 \mathrm{~m}$ sampai $200 \mathrm{~m}$ dari garis pantai kadang tidak ditegaskan atau dibebaskan sehingga mengabaikan segi keamanan, perlindungan dan aturan pemerintah. Hal ini menunjukkan bahwa beberapa 
wilayah pesisir kita sudah tidak aman mengingat Indonesia adalah wilayah yang rawan terhadap bencana. Fenomena bencana menurut data yang diperoleh dari BNPD bahwa diwilayah majene paling sering terjadi bencana angin musim dimana ini sangat berdampak terhadap tempat tinggal warga. Hal ini berdampak terhadap bentuk rumah dan bangunan yang ada diwilayah tersebut. Perubahan bentuk rumah awal ke rumah bentuk sekarang ini tentunya memberikan pengaruh terhadap typoogi bentuk rumah Nelayan khususnya.

\section{Metode}

Lokasi penelitian ini secara administraif dilakukan pada Kawasan Permukiman Nelayan di Kelurahan Rangas Kecamatan Banggae, Majene Sulawesi Barat. Data penelitian berupa dokumentasi dilapangan dan mencatat jenis typology rumah nelayan di lokasi survey,kemuadian data diklasifikasikan dalam tabel matriks, dengan mengamati semua unsur arsitektural dan tipologi rumah di pesisir pantai dan area sekitarnya. Data akan dianalisis dan disingkronkan selanjutnya. Pengolahan data dilakukan dengan cluster (pengelompokan) dalam bentuk matriks dengan melihat faktor yang dianggap berpengaruh terhadap tipologi rumah yang tanggap bencana, pendekatan ini dengan melihat beberapa unsur rumah fisik dan non fisik, diantaranya adalah Struktur Rumah, bahan yang digunakan, posisi tempat(orientasi terhadap laut dan rumah warga), kondisi lahan, zona permukiman, prasarana dan sarana (jalan dan tempat umum/fasiltas yang ada) yang dibagi berdasarkan pengelompokannya.sedangkan non fisik ditinjau dari segi berdasarkan ketentuan Hukum, peraturan perundangan, politik,ekonomi dan sosial budaya. Survey ini dicatat dengan gambar sketsa.dan mengambil titik koordinat posisinya yg dideteksi dgn GPS dan dituang dalam peta digitasi. analisis data yang digunakan dalam penelitian ini adalah ; Karakteristik Analisis Tipologi rumah dengan pendekatan terhadap kerawanan bencana pada kawasan Permukiman Nelayan ini akan dianalisis berdasarkan kelompok/zonanya.

Hasil dari pengelompokan tipologi rumah masing masing zona ini akan disajikan dalam bentuk matriks sehingga lebih jelas Tipology pola permukiman dan selanjutnya menganalisis beberapa faktor pengaruh typologi terhadap rumah tanggap bencana di Kawasan Tanjung Rangas Majene. Analisis ini disajikan dengan penjelasan deskriptif dengan merujuk pada beberapa literatur pendukung analisa.

\section{Results}

\section{Tinjauan Fisik Wilayah Penelitian}

Kelurahan Rangas terletak di Kecamatan Banggae. Berdasarkan letak geografisnya Kecamatan Banggae berada pada 20 38' 45" - 30 38' 15" Lintang Selatan dan antara 1180 45' 00" - 1190 4' 45"Bujur Timur. Batas wilayahnya kelurahan ini, sebelah utara berbatasan dengan Kecamatan Pamboang, di sebelah Timur berbatasan dengan Kabupaten Polewali Mandar, sebelah Barat berbatasan dengan selat Makassar dan sebelah Selatan Teluk Majene. 


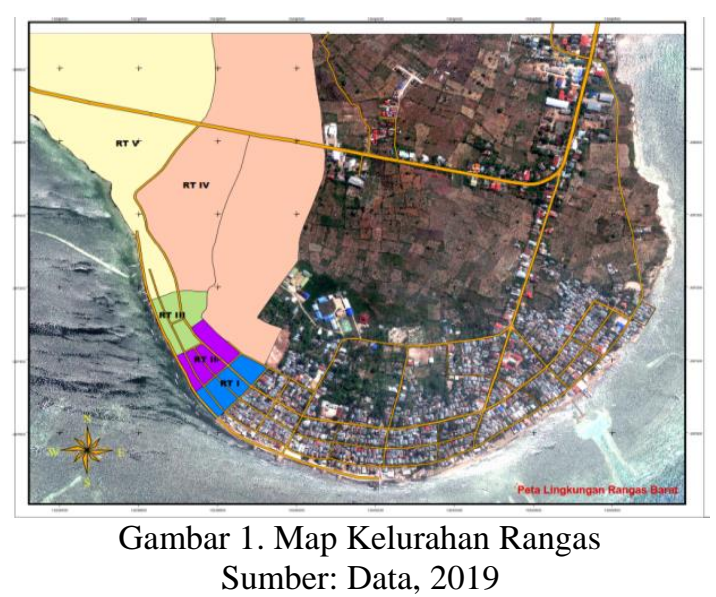

Data statistik Kecamatan Banggae dalam Angka 2018, Kecamatan Banggae terdiri dari 8 wilayah Desa/ kelurahan dengan luas masing masing kelurahan ; Totoli (4,33 Km2), Rangas (2,23 km2), Pangali Ali( 4,49 km2), Banggae (2,27 km2), Galung (2,14 km2), Palipi Soreang $(4,12 \mathrm{~km} 2)$, serta Pamboborang $(3,11 \mathrm{~km} 2)$.

Pada permukiman Nelayan di Kelurahan Rangas ini merupakan kelurahan yang terpadat penduduknya dibandingkan dengan kelurahan lainnya yang ada di kecamatan Banggae. dibagi atas 4 lingkungan; Lingkungan Rangas Barat, lingkungan Rangas Timur dan lingkungan Tamalassu dan Pabesoang. Berdasarkan data Kantor kelurahan Rangas Jumlah penduduk sampai tahun 2019 di Kelurahan Rangas sebanyak 7664 jiwa, di lingkungan Rangas Barat sekitar 1812 jiwa Penduduk, di lingkungan Rangas Timur sebanyak 2184 jiwa, di lingkungan Tamalassu sebanyak 1666 jiwa dan di Pa'besoaang sebanyak 2002 jiwa penduduk. Banyaknya Bangunan di kelurahan Rangas, rumah sebanyak 1388 unit, gardu 65 unit, sekolah 12 unit, kantor 2 unit, masjid 6 unit, asrama 2 unit, posyandu 4 unit, pasar 2 unit, dan pekuburan terdapat 8 lokasi pekuburan. Luas wilayah kelurahan Rangasi $621 \mathrm{Ha}$. Lingkungan Rangas Timur $154 \mathrm{Ha}$, Lingkungan Rangas Tamalassu $150 \mathrm{Ha}$, lingkungan Rangas Paa'besoang $130 \mathrm{Ha}$ dan di lingkungan Rangas Barat $187 \mathrm{Ha}$. Terdapat 1771 Kepala Keluarga, dan 18 Rukun Tetangga.

Letak dan klasifikasi desa/kelurahan di Kecamatan Banggae dikelompokkan atas ; lahan berada di tepi laut dan bukan tepi laut. Kelurahan yang berada pada area tepi laut (coastal area) diantaranya; kelurahan/desa Totoli, kelurahan Palipi Soreang, kelurahan Rangas, Kelurahan Baru, kelurahan Pangali Ali dan Kelurahan Banggae. Sedangkan kelurahan yang tidak berada di tepi laut, Kelurahan Pamboborang dan Kelurahan Galung.

\section{Tinjauan Sarana dan Prasana pada lokasi penelitian Penelitian}

Pada Kelurahan Rangas terdapat 1.388 unit rumah tinggal dan 65 unit kios/gardu. Kelompok Rumah di kelurahan ini, di kelompokkan berdasarkan jenis rumah batu sebanyak 696 unit dan rumah kayu sebanyak 692 unit.

Tabel.1 Data Jumlah Bangunan dan Klasifikasi Bangunan di Kelurahan Rangas Majene

\begin{tabular}{|c|c|c|c|c|c|c|c|c|c|c|c|c|c|}
\hline & \multirow{3}{*}{$\begin{array}{c}\text { NAMA } \\
\text { LINGKUNGAN }\end{array}$} & \multicolumn{12}{|c|}{ KLASIFIKASI BANGUNAN } \\
\hline & & \multicolumn{3}{|c|}{ MILIK PENDUDUK } & \multicolumn{5}{|c|}{ MILIK PEMERINTAH/SWASTA } & \multicolumn{4}{|c|}{ SARANA DAN PRASARANA } \\
\hline & & $\begin{array}{c}\text { Rumah } \\
\text { Batu }\end{array}$ & $\begin{array}{l}\text { Rumah } \\
\text { Kayu }\end{array}$ & $\begin{array}{c}\text { Gard } \\
\mathbf{u} / \\
\text { Kios }\end{array}$ & Kantor & Sekolah & Puskesmas & Posyandu & Asrama & $\begin{array}{l}\text { Masjid/ } \\
\text { Mushallah }\end{array}$ & Gereja & Pasar & Kuburan \\
\hline 1 & 2 & 3 & 4 & 5 & 6 & 7 & 8 & 9 & 10 & 11 & 12 & 13 & 14 \\
\hline 1 & Rangas Timur & 216 & 319 & 20 & 0 & 4 & 0 & 1 & 0 & 1 & 0 & 0 & 2 \\
\hline 2 & Rangas Tamalassu & 170 & 114 & 14 & 0 & 0 & 0 & 1 & 0 & 1 & 0 & 1 & 1 \\
\hline 3 & Rangas Pa'Besoang & 198 & 147 & 16 & 1 & 8 & 0 & 1 & 0 & 2 & 0 & 1 & 2 \\
\hline
\end{tabular}




\begin{tabular}{ccccccccccccc}
4 & Rangas Barat & 112 & 112 & 15 & 1 & 0 & 0 & 1 & 2 & 2 & 0 & 0 \\
\hline Jumlah & $\mathbf{6 9 6}$ & $\mathbf{6 9 2}$ & $\mathbf{6 5}$ & $\mathbf{2}$ & $\mathbf{1 2}$ & $\mathbf{0}$ & $\mathbf{4}$ & $\mathbf{2}$ & $\mathbf{6}$ & $\mathbf{0}$ & $\mathbf{2}$ & $\mathbf{8}$ \\
\hline Sumber : (olah Data Kantor Kelurahan, 2019) & & &
\end{tabular}

Tabel.2. Data Jumlah Bangunan dan Klasifikasi Bangunan di Kelurahan Rangas Majene

\begin{tabular}{|c|c|c|c|c|c|c|c|c|c|c|c|}
\hline \multirow[b]{2}{*}{ Tahun } & \multirow{2}{*}{$\begin{array}{l}\text { Jumlah } \\
\text { Kejadian }\end{array}$} & \multicolumn{3}{|c|}{ Korban (jiwa) } & \multicolumn{4}{|c|}{ Rumah (unit) } & \multicolumn{3}{|c|}{ Kerusakan (unit) } \\
\hline & & $\begin{array}{l}\text { Meninggal \& } \\
\text { Hillang }\end{array}$ & $\begin{array}{l}\text { Luka- } \\
\text { luka }\end{array}$ & $\begin{array}{c}\text { Menderita \& } \\
\text { mengungsi }\end{array}$ & $\begin{array}{c}\text { Rusak } \\
\text { Berat }\end{array}$ & $\begin{array}{l}\text { Rusak } \\
\text { Sedang }\end{array}$ & $\begin{array}{l}\text { Rusak } \\
\text { Ringan }\end{array}$ & Terendam & $\begin{array}{l}\text { Fasilitas } \\
\text { Kesehatan }\end{array}$ & $\begin{array}{l}\text { Fasilitas } \\
\text { Peribadatan }\end{array}$ & $\begin{array}{c}\text { Fasilitas } \\
\text { Pendidikan }\end{array}$ \\
\hline 2014 & 1 & 0 & 1 & 0 & 0 & 0 & & 0 & 0 & & \\
\hline 2009 & 1 & 216 & 34 & 0 & 0 & 0 & & 0 & 0 & & \\
\hline 2005 & 1 & 1 & 580 & 0 & 0 & 0 & & 0 & 0 & & \\
\hline Jumlah & 3 & 217 & 615 & 0 & 0 & 0 & & 0 & 0 & & \\
\hline
\end{tabular}

Sumber : (Data Informasi Bencana Indonesia BNPD, 2019)

\section{Pembahasan}

\section{Typologi Rumah Nelayan di Kawasan permukiman Nelayan di Tanjung Rangas Kabupaten Majene.}

Berdasarkan informasi dari kelurahan setempat type bangunan pada kelurahan Rangas diklasifikasi dalam 3 kelompok yakni; kategori rumah batu, rumah kayu dan gardu. Umummya bangunannya yang awalnya berbentuk rumah panggung namun setelah direnovasi rumah ini berubah menjadi rumah yang berbentuk dua tingkat dengan lantai bawah dibuat ruang tambahan yang dilapisi dinding pasasangan batu bata. Pada lantai atasnya adalah rumah panggung. Dari analisa penulis bahwa pada beberapa kasus berubahnya rumah panggung ini hampir sebagian besar telah merubah bentuk dengan penambahan ruang pada bawah rumah panggungnya.

Rumah nelayan yang dijadikan sampel penelitian tersebar di setiap lingkungan yang dipilih secara acak yang dapat mewakili setiap lingkungan kelurahan. Terkait dengan kebencanaan typologi bangunan pada rumah nelayan di Kelurahan Rangas ini dipengaruhi oleh beberapa faktor. Analisa ini akan dilakukan dengan melihat bentuk/model bangunan, system konstruksi yang digunakan dan keadaan ruang spasial pada yang ditempati bangunan. Kemudian indikatornya dengan mengukur tanggap kebencanaannya terhadap beberapa faktor terkait typology bangunan tersebut. Sampel yang terpilih dari tiap lingkungan berdasarkan pembagian kelompok type bangunannya dikelurahan Rangas terlihat dalam tabel berikut:

Tabel 3. Rumah yang mewakili Sampel Penelitian setiap Lingkungan di Kelurahan Rangas

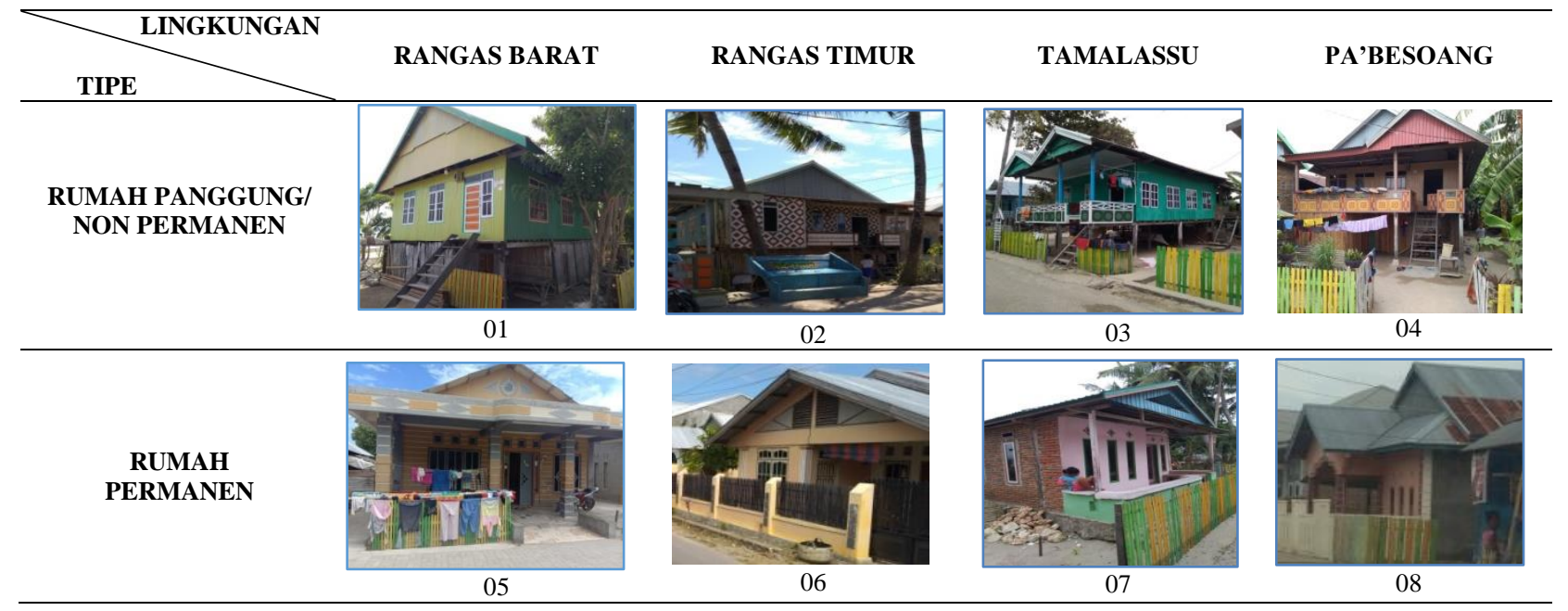




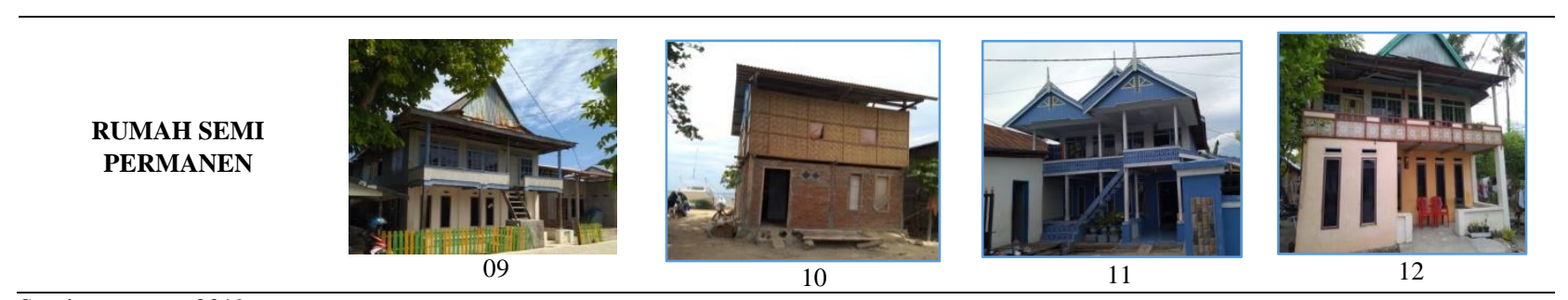

Sumber: survey, 2019

Di Kecamatan Rangas terdapat terdapat variasi model rumah. Namun sebenarnya awalnya adalah pada umumnya masyarakat nelayan menggunakan rumah panggung. Dan kemudian akhirnya berkembang menjadi rumah panggung yang di tambahkan ruang pada bagian bawah kolong rumah dan menaikkan bagian atas rumah. Pengelompokan rumah berdasarkan hasil analisa dari penulis mengklasifikasikan dalam 3 type kelompok rumah yang ada di Kelurahan Rangas Majene, yakni; pertama, rumah dengan bentuk Panggung/Non Permanen, yaitu: Bangunan rumah dengan bentuk rumah Panggung yang bentuknya lebih fungsional atau persegi panjang dengan ukuran biasanya sekitar $7.5 \mathrm{M}$ 9.0 M x 9.0 M - 12.0 M. Kedua, rumah dengan bentuk Permanen, yaitu ; model rumah yang solid dengan selubung dinding memakai pasangan batu bata, umumnya model atap pada bangunan ini berbentuk pelana atau berbentuk limasan. Ketiga, rumah dengan bentuk Semi Permanen/semi Panggung, yaitu: pada bangunan rumah ini terdapat dua lantai dengan bentuk awalnya adalah rumah panggung yang kemudian direnovasi dengan menambahkan ruang bawah bangunan rumah dengan menutupi dinding keliling yang menyesuaikan batas denahnya dari acuan rumah panggung tersebut.

\section{Bentuk dan Konstruksi Bangunan Rumah Nelayan di Kelurahan Rangas}

Bentuk bangunan rumah nelayan di Kelurahan Rangas awalnya mulanya adalah konstruksi rumah panggung yang diadopsi dari rumah tradisional arsitektur Mandar. Namun seiring waktu perlahan telah banyak yang merenovasi menjadi rumah semi permanen dan bahkan merenovasi total bangunan rumahnya menjadi rumah permanen. Rumah permanen ini semakin berkembang khusnya diarea sepanjang jalan masuk ke kelurahan Rangas yang terletak di Rangas Timur. Rumah panggung yang berarsitektur mandar membagi bentuk rumah dalam kepala, badan dan kaki, meliputi atap sebagai bagian kepala ,lantai, ruang dan dinding rumah sebagai badn kos,an rumah dan tiang/kolong dengn umpaknya sebagai kaki. Berdasarkan Kosmologi bentuk rumah maka akan dianalisa bentuk dan kontruks bangunan secara berurutan berdasarkan type rumah per lingkungan, dianalisa sebagai berikut :

\section{Bentuk Atap dan konstruksinya}

Dalam fungsinya atap adalah merupakan penutup seluruh ruang yang ada dibawahnya, sehingga dapat melindungi rumah dari panas, hujan, angin dan binatang buas serta keamanan. Pengaruh iklim sangat menjadi pertimbangan dalam menentukan desain bentuk dan konstruksinya. Fungsi atap rumah dapat menjadi payung yang dapat melindungi sisi rumah dari gangguan cuaca (panas, hujan dan angin) sehingga bagian struktur dan konstruksinya harus kokoh dan kuat. Atap sangat besar pengaruhnya terhadap resiko bencana alam maupun non alam terhadap pemiliknya salah satunya terhadap angin musim yang dikenal warga sangat riskan dikawasan ini. Dalam penelitian terdahulu yang telah dilakukan oleh beberapa peneliti dengan menggunakan metode wind tunnel ataupun dengan simulasi CFD, Tominage et al (2015) dalam penelitiannya menganalisis aliran angin berdasarkan sudut dari perbandingan antara ketinggian dan lebar atap. Penelitian mengenai bentuk atap inti dengan tujuan untuk mendapatkan efektifnya bentuk atap terhadap daya tahan angin, yang tentu berpengaruh terhadap bentuk dan struktur bangunan sehingga mampu beradaptasi saat kondisi angin kencang. Indonesia umumnya bentuk atap 
rumah tradisional adalah jenis atap pelana, dengan kemiringan besar sudut atap yakni $0^{\circ}$, $15^{\circ}, 30^{\circ}, 45^{\circ}$, dan $60^{\circ}$ variabel terikat terdiri atas pola aliran angin di sekitar atap dan besar koefisien aerodinamis model uji yang terlihat dari nilai drag force. Pada kasus dikelurahan Rangas ini, akan di lihat kesesuaian bentuk atap dan konstruksinya pada tanggapnya bangunan dan penghuninya terhadap kebencanaan. Maka berdasarkan kelompok atau type bangunan akan dianalisa model atap sebagai beruikut:

\section{Tipe dan bentuk atap rumah di kelurahan Rangas}

a. Bentuk Bangunan type rumah Non Permanen pada kelurahan Rangas ini berbentuk rumah panggung khas arsitektur tradisional Mandar, biasanya terdapat ruang bagian bawah rumah atau kolong rumah yang ditutupi dengan menggunakan bilah bambu pada keliling/selubungnya. Namun seiring waktu sudah banyak yang mendirikan rumah melenceng dari ciri rumah arsitektur tradisional mandar. Luas rumah panggung ini biasanya sekitar $7.5 \mathrm{M}-9.0 \mathrm{M}$ x $9.0 \mathrm{M}-12.0 \mathrm{M}$ yang biasanya terdapat jarak lahan antar rumah sekitar 2 meter. Berdasarkan data kantor kelurahan Rangas terdapat 692 rumah kayu, kategori rumah kayu yang dimaksud ini termasuk rumah semi permanen yang awalnya adalah rumah panggung. Di lingkungan Rangas Barat terdapat 112 rumah kayu. Bentuk atap pada rumah Panggung di lingkungan Rangas Barat umumnya berbentuk pelana dengan ciri khas arsitektur mandar, kemiringan atapnya $30^{\circ}$ sampai $40^{\circ}$. Pada bagian depan atap tertutup seng tanpa timpalaja. Material rangka kuda menggunakan kayu bahan lokal setempat, sedangkan penutup atapnya memakai penutup seng.

b. Di lingkungan Rangas Timur terdapat 319 rumah kayu berdasarkan data kantor kelurahan Rangas, yang termasuk didalam rumah semi permanen. Bentuk atap umumnya sama menggunakan atap pelana tanpa timpalaja yang bagian depannya ditutupi dengan seng. Sudut kemiringan atapnya 30 derajat sampai 40 derajat yang kadang di teras depan menggunakan kemiringan atap 0 sampai 15 derajat. Penutup atapnya juga menggunakan material seng.

c. Pada lingkungan Rangas Pa'Besoang dan Rangas Tamalassu model dan bentuk atapnya juga pelana namun ada beberapa rumah yang terdapat di lingkungan Pa'Besoang dan Tamalassu variasi seperti yang terlihat digambar, terdapat 2 atap pelana pada satu rumah dan sudah memiliki variasi timpalaja namun tetap tertutup dengan seng pada area depannya. Kemiringan atapnya hampir sama dengan model atap dilingkungan yang lainnya. Dan menggunakan penutup atap Seng.

Dari data dianalisa bahwa, penggunaan bentuk atap disetiap lingkungan di kelurahan Rangas umumnya berbentuk pelana dengan kemiringan 30 derajat sampai 40 derajat dan sebagiannya datar dengan kemringan atap 0 sampai 15 derajat yang penggunaanya biasanya pada atap teras depan rumah. Response terhadap kebencanaan dalam hal ini adalah bahwa ketika angin musim Timur datang, keluhan warga yang sering dirasakan adalah beberpa atap rumahnya terbawa angin kencang atau bencana puting beliung. Berdasarkan referensi bahwa kemiringan atap 40 derajat ke atas memberikan tekanan beban angin yang lebih besar sehingga menambah resiko rawan terhadap bencana. Kemiringan atap yang landai bebannya akan lebih kecil.

\section{Bentuk Atap pada rumah Permanen di kelurahan Rangas}

a. Bentuk Atap pada rumah pemanen di kelurahan Rangas kawasan permukiman nelayan: pada umumnya berbentuk pelana atau limasan dengan variasi kemiringan atap $0^{\circ}, 15^{\circ}, 30^{\circ}$ dan $400^{\circ}$. Di lingkungan Rangas Barat warga menggunakan atap dengan variasi kemiringan dan macam bentuknya. Tampak di gambar 1. Rumah permanen yang dibuat warga dengan menggunakan penutup atap seng sebagian 
kecilnya menggunakan bahan spandek menggunakan model pelana dengan kemiringan atap sekitar $30^{\circ}$ pada umumnya, namun adapula yang menggunakan atap rumah dengan kemiringan $0^{\circ}$ sampai $15^{\circ}$ umumnya menggunakan material seng sebagai penutup karna bahan ini mudah didapat.

b. Di lingkungan Rangas Timur juga banyak yang menggunakan bentuk atap pelana. Gerbang Kawasan permukiman Nelayan ini berada di lingkungan Rangas Timur. Sehingga bangunan yang ada di Rangas pada area sebelah luar kawasan permukiman yang mengarah ke akses keluar kelurahan kebanyakan memiliki model rumah dengan type bentuk permanen. Atap umumnya berbentuk pelana dengan penutup materialnya menggunakan seng atau spandek.

c. Pada lingkungan Tamalassu dan lingkungan $\mathrm{Pa}$ 'Besoang bentuk atap pada rumah permanen ini menggunakan model atap pelana yang hampir sama dengan rumah permanen di lingkungan Rangas Barat dan Rangas Timur sedikit penggunaan atap jurai yang terdapat di bagaian depan tambahab ruang. Pada sisi depan atap biasanya tertutup dengan ornamen sederhana dan bahkan tanpa ornament sama sekali. Penggunaan timpa laja pada rumah permanen hampir tidak dipakai. Fungsionalnya atap sengaja dibuat seperti itu karna lebih memilih untuk amannya atap terhadap terpaan angin kencang yang terjadi di wilayah ini.

\section{Tipe bangunan rumah semi permanent/semi panggung di Kelurahan Rangas}

a. Bentuk Atap rumah Semi Permanen di Lingkungan Rangas Barat ini berbentuk pelana dan atap pelat landai/datar pada bagian teras depan dan tamping disisi kiri dan kanannya.

Kemiringan atap utama 38 derajat dan kemiring atap teras $/$ tamping $5^{\circ}-10^{\circ}$. Material penutup atap menggunakan seng dengan rangka kuda kuda kayu, lisplanknya menggunakan kayu, tampa timpalaja hanya ditutup seng.

b. Pada lingkungan Rangas Timur, bentuk atap rumah pada sampel berbentuk pelana dengan dengan menggunakan penutup atap dari seng dan menggunakan kuda-kuda rangka kayu.tanpa timbanglayang. Lisplank umumnya menggunakan kayu bahkan tanpa lisplank.

c. Pada lingkungan Tamalassu dan lingkungan Pa'besoang terdapat variasi bentuk atap , pada Rumah di lingkungan Tamalassu ini menggunakan tiga atap bentuk pelana dengan menggunakan timpalaja yang ditutup dengan material seng yang berlapis dua. Penutup atapnya menggunakan seng dengan plafond dari triplek dan lisplank dengan menggunakan papan kayu.

Analisa bentuk atap di beberapa lingkungan di kelurahan Rangas ini menunjukan bahwa pada umumnya bentuk atap pada rumah nelayan di kelurahan Rangas ini berbentuk atap pelana dengan kemiringan atap sekitar $35^{\circ}$ sampai $42^{\circ}$ selain itu rumah kadang memiliki tambahan atap datar teras depan dan tamping kiri kanannya dengan kemiringan atap $5^{\circ}$ sampai $15^{\circ}$. Bentuk atap yang ditabulasi menurut type rumah di tipa lingkungan. 


\section{Tabel. 2. Analisa Bentuk Atap dan Konstruksi berdasarkan type Rumah per lingkungan di Kelurahan Rangas}

\begin{tabular}{|c|c|c|c|c|}
\hline No. & Lingkungan & Type & Material & BentukAtap \\
\hline \multirow[t]{3}{*}{1} & \multirow[t]{3}{*}{ Rangas Barat } & Rumah Panggung & $\begin{array}{l}\text { Penutup : seng, } \\
\text { kontrusksi: kayu klsI } \\
\text { Timpalaja : seng } \\
\text { Lisplank : kayu kls I } \\
\text { Plafond : kayu kls II }\end{array}$ & $\begin{array}{l}\text { Atap pelana } \\
\text { kemiringan } 40^{\circ}\end{array}$ \\
\hline & & Rumah & $\begin{array}{l}\text { Penutup : seng, } \\
\text { Konstruksi: kayu dan beton } \\
\text { Timpalaja : seng } \\
\text { Lisplank : kayu kls I } \\
\text { Plafond : kayu kls II }\end{array}$ & $\begin{array}{l}\text { Atap pelana } \\
\text { kemiringan } 35^{\circ}- \\
37^{\circ} \text { dan Teras } \\
\text { depan pelat beton }\end{array}$ \\
\hline & & R. Semi permanen & $\begin{array}{l}\text { Penutup : seng, } \\
\text { Konstruksi: kayu klsI } \\
\text { Timpalaja : seng } \\
\text { Lisplank : kayu kls I } \\
\text { Plafond } \quad \text { : kayu kls II }\end{array}$ & $\begin{array}{l}\text { Atap pelana } \\
\text { kemiringan } 40^{\circ} \\
\text { Teras dan } \\
\text { tamping kiri } \\
\text { kanan } 10^{\circ}\end{array}$ \\
\hline \multirow[t]{3}{*}{2} & \multirow[t]{3}{*}{ Rangas Timur } & Rumah Panggung & $\begin{array}{l}\text { Penutup : seng, } \\
\text { Konstruksi: kayu klsI } \\
\text { Timpalaja : seng } \\
\text { Lisplank :Kayu kls I } \\
\text { Plafond : kayu II }\end{array}$ & $\begin{array}{l}\text { Atap pelana } \\
\text { kemiringan } 37^{\circ} \text {. } \\
\text { Teras dan } \\
\text { Tamping kiri } \\
\text { kanan } 10^{\circ}\end{array}$ \\
\hline & & Rumah Permanen & $\begin{array}{l}\text { Penutup : Spandek } \\
\text { Konstruksi: kayu klsI } \\
\text { Timpalaja }: \text { kusen jalusi } \\
\text { Lisplank } \quad \text { : Kayu } \\
\text { Plafond } \quad \text { : eternity }\end{array}$ & $\begin{array}{l}\text { Atap pelana } \\
\text { kemiringan } 30^{\circ} \text {. } \\
\text { Tanpa teras }^{\circ}\end{array}$ \\
\hline & & R.Semi Permanen & $\begin{array}{l}\text { Penutup : seng, } \\
\text { Konstruksi: kayu klsI } \\
\text { Timpalaja : seng } \\
\text { Lisplank : - } \\
\text { Plafond : - }\end{array}$ & $\begin{array}{l}\text { Atap pelana } \\
\text { kemiringan } 38^{\circ} \text {. } \\
\text { Tanpa atap teras }\end{array}$ \\
\hline \multirow[t]{3}{*}{3} & Tamalassu & Rumah Panggung & $\begin{array}{l}\text { Penutup : seng, } \\
\text { Konstruksi: kayu klsI } \\
\text { Timpalaja : seng lapis } 2 \\
\text { Lisplank } \quad \text { : kayu lapis seng } \\
\text { Plafond : triplek }\end{array}$ & $\begin{array}{l}\text { Atap pelana } 2 \text { bh } \\
\text { kemiringan } 42^{\circ} \text {. } \\
\text { dengan timpalaja }\end{array}$ \\
\hline & & Rumah Permanen & $\begin{array}{l}\text { Penutup : seng, } \\
\text { Konstruksi: kayu klsI } \\
\text { Timpalaja : seng dlubangi } \\
\text { Lisplank : papan kayu } \\
\text { Plafond : - }\end{array}$ & $\begin{array}{l}\text { Atap pelana } \\
\text { kemiringan } 37^{\circ} \text {. } \\
\text { Teras dan } \\
\text { Tamping kiri } \\
\text { kanan } 10^{\circ}\end{array}$ \\
\hline & & R. Semi Permanen & $\begin{array}{l}\text { Penutup : seng, } \\
\text { Konstruksi: kayu klsI } \\
\text { Timpalaja : seng } \\
\text { Lisplank } \quad \text { : kayu lapis seng } \\
\text { Plafond : Triplek } \\
\text { Anjong : seng ornament }\end{array}$ & $\begin{array}{l}\text { Atap pelana } 3 \mathrm{bh} \\
\text { kemiringan } 40^{\circ} \text {. }\end{array}$ \\
\hline 4 & Pa'besoang & Rumah Panggun & $\begin{array}{l}\text { Penutup : seng, } \\
\text { Konstruksi: kayu klsI } \\
\text { Timpalaja : seng } \\
\text { Lisplank }: 45\end{array}$ & $\begin{array}{l}\text { Atap pelana } \\
\text { kemiringan } 45^{\circ} \text {. } \\
\text { Teras dan } \\
\text { Tamping kiri }\end{array}$ \\
\hline
\end{tabular}




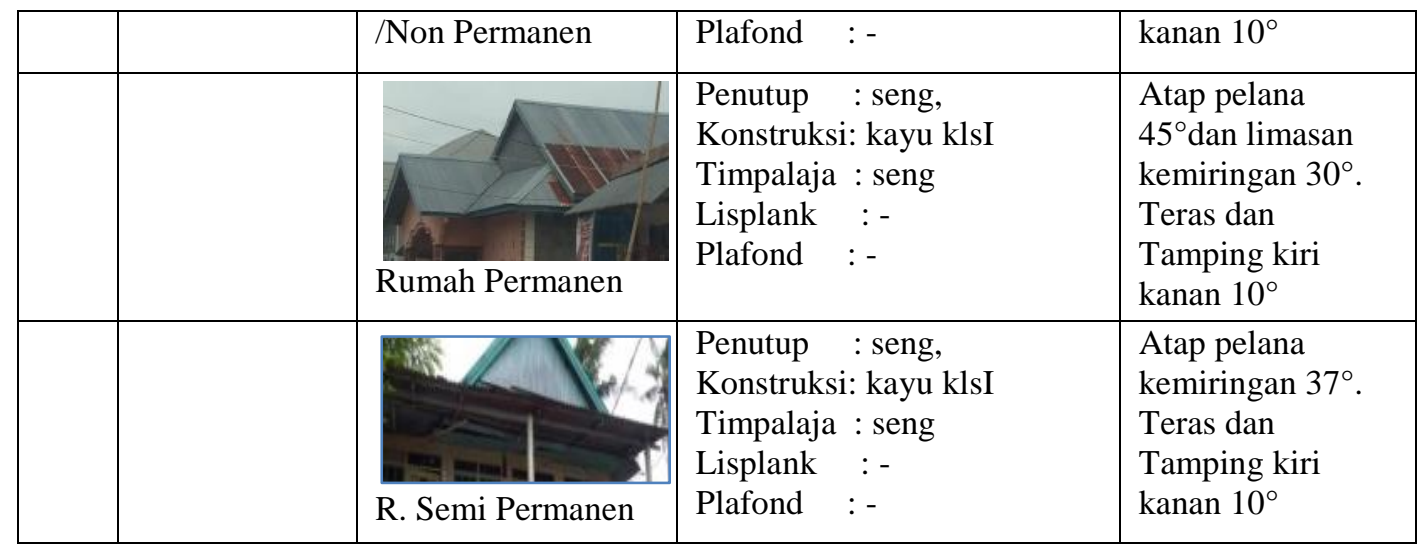

\section{Bentuk Denah, Tampak dan pembagian ruang pada bangunan rumah nelayan di Kelurahan Rangas}

a. Rumah 01. Type Rumah Panggung di lingkungan Rangas Barat

Denah berbentuk segi empat panjang dengan ukuran bangunan panjang 7,5 $\mathrm{m}$ dan lebar 9 meter. Bangunan ini system panggung dengan lantai bawah terdapat ruang untuk ternak/ peralatan nelayan dan di lantai atas terdapat ruang ruang yakni ruang tamu, Kamar tidur, ruang keluarga dan ruang makan/dapur. Biasanya Teras berada diposisi depan sebelum masuk keruang tamu. Namun pada kasus di rumah 01 ini tidak terdapat teras rumah bagian depan. Ukuran teras 1 meter $\mathrm{x}$ panjang rumah dikurangi ukuran tempat letak tangga yang ukuran tangganya adalah $1.00 \mathrm{~m} \times 2.50$ meter. Jumlah tangga biasanya berjumlah ganjil, dengan bilangan 5, 7, atau 9. Pada rumah 01 terdapat 9 buah anak tangga. Bentuk rumah panggung ini memiliki ketinggian tiang untuk kolom rumah sekitar $2.00 \mathrm{~m}$ dengan material kayu yang menggunakan umpak pada bagian bawah tiang /kolom agar tidak menyentuh langsung ke tanah. Pada kolong rumah ini biasa dimanfaatkan sebagai ruang tambahan. Tampak bangunan rumah 01 ini, berbentuk rumah panggung dengan dinding penutupnya menggunakan material seng sebagai selubung bangunan tanpa ornamen. Menggunakan jendela kaca dengan kusen jendela dan pintu terbuat dari kayu. Ukuran jendela $70 \mathrm{~cm}$ x $110 \mathrm{~cm}$. terdapat 3 buah jendela pada sisi depan dan masing masing 3 buah di samping kiri dan kanannya. Pintu yang digunakan adalah model pintu panil dari kayu Jati. Pada ruang bawah terdapat dinding yang menutupi ruang tambahan dengan bilah bambu ruang ini biasanya di gunakan untuk tempat ternak dan tempat penyimpanan peralatan nelayan bagi pemiliknya.

b. Rumah 02. Type Rumah Panggung di lingkungan Rangas Timur

Denah berbentuk segi empat panjang dengan ukuran bangunan panjang $9 \mathrm{~m}$ dan lebar 12 meter. Bangunan ini system panggung dengan lantai bawah terdapat ruang untuk ternak/ peralatan nelayan dan di lantai atas terdapat ruang ruang yakni ruang tamu, Kamar tidur, ruang keluarga dan ruang makan/dapur. Biasanya Teras berada diposisi depan sebelum masuk keruang tamu. Ukuran teras 1.00 meter $\mathrm{x} 4.00$ meter dikurangi ukuran tempat letak tangga yang ukuran tangganya adalah $1.00 \mathrm{~m} \times 2.50$ meter. Jumlah tangga biasanya berjumlah ganjil, dengan bilangan 5, 7, atau 9 . Bentuk rumah panggung ini memiliki ketinggian tiang untuk kolom rumah sekitar $2.00 \mathrm{~m}$ dengan material kayu yang menggunakan umpak pada bagian bawah tiang /kolom agar tidak menyentuh langsung ke tanah. Pada kolong rumah ini biasa dimanfaatkan sebagai ruang tambahan. Tampak bangunan rumah $02 \mathrm{ini}$, berbentuk rumah panggung dengan dinding penutupnya menggunakan material papan kayu 
sebagai selubung bangunan dengan ornamen. Menggunakan jendela kaca dengan kusen jendela dan pintu terbuat dari kayu. Ukuran jendela $60 \mathrm{~cm} \times 110 \mathrm{~cm}$. terdapat 2 buah jendela pada sisi depan dan masing masing 3 buah di samping kiri dan kanannya. Pintu yang digunakan adalah model pintu panil dari kayu Jati. Pada ruang bawah terdapat dinding yang menutupi ruang tambahan dengan bilah bambu ruang ini biasanya di gunakan untuk tempat ternak dan tempat penyimpanan peralatan nelayan bagi pemiliknya

c. Rumah 03. Type Rumah Panggung di lingkungan Tamalassu

Denah berbentuk segi empat panjang dengan ukuran bangunan panjang 7,5 $\mathrm{m}$ dan lebar 12 meter. Bangunan ini system panggung dengan lantai bawah terdapat ruang untuk ternak/ peralatan nelayan dan di lantai atas terdapat ruang ruang yakni ruang tamu, Kamar tidur, ruang keluarga dan ruang makan/dapur. Biasanya Teras berada diposisi depan sebelum masuk keruang tamu. Ukuran teras 1.00 meter $\times 7.50$ meter dikurangi ukuran tempat letak tangga yang ukuran tangganya adalah $1.00 \mathrm{~m} \times 2.50$ meter. Jumlah tangga biasanya berjumlah ganjil, dengan bilangan 5, 7, atau 9 . Bentuk rumah panggung ini memiliki ketinggian tiang untuk kolom rumah sekitar $2.00 \mathrm{~m}$ dengan material kayu yang menggunakan umpak pada bagian bawah tiang /kolom agar tidak menyentuh langsung ke tanah. Pada kolong rumah ini biasa dimanfaatkan sebagai ruang tambahan. Tampak bangunan rumah $02 \mathrm{ini}$, berbentuk rumah panggung dengan dinding penutupnya menggunakan material papan kayu sebagai selubung bangunan tanpa ornamen. Menggunakan jendela kaca dengan kusen jendela dan pintu terbuat dari kayu. Ukuran jendela $120 \mathrm{~cm} \times 110 \mathrm{~cm}$. terdapat 2 buah jendela pada sisi depan dan masing masing 4 buah di samping kiri dan kanannya. Pintu yang digunakan adalah model pintu panil dari kayu Jati. Pada ruang bawah terdapat dinding yang menutupi ruang tambahan dengan bilah bambu ruang ini biasanya di gunakan untuk tempat ternak dan tempat penyimpanan peralatan nelayan bagi pemiliknya.

d. Rumah 04. Type Rumah Panggung di lingkungan Pa'besoang

Denah berbentuk segi empat panjang dengan ukuran bangunan panjang 7,5 $\mathrm{m}$ dan lebar 12 meter. Bangunan ini system panggung dengan lantai bawah terdapat ruang untuk ternak/ peralatan nelayan dan di lantai atas terdapat ruang ruang yakni ruang tamu, Kamar tidur, ruang keluarga dan ruang makan/dapur. Biasanya Teras berada diposisi depan sebelum masuk keruang tamu. Ukuran teras 1.00 meter x 7.50 meter dikurangi ukuran tempat letak tangga yang ukuran tangganya adalah $1.00 \mathrm{~m} \times 2.50$ meter. Jumlah tangga biasanya berjumlah ganjil, dengan bilangan 5, 7, atau 9 . Bentuk rumah panggung ini memiliki ketinggian tiang untuk kolom rumah sekitar $2.00 \mathrm{~m}$ dengan material kayu yang menggunakan umpak pada bagian bawah tiang /kolom agar tidak menyentuh langsung ke tanah. Pada kolong rumah ini biasa dimanfaatkan sebagai ruang tambahan. Tampak bangunan rumah $02 \mathrm{ini}$, berbentuk rumah panggung dengan dinding penutupnya menggunakan material papan kayu sebagai selubung bangunan dan pada dinding teras depan menggunakan kayu dengan hiasan ornamen. Menggunakan jendela kaca dengan kusen jendela dan pintu terbuat dari kayu. Ukuran jendela $70 \mathrm{~cm} \times 110 \mathrm{~cm}$. terdapat 2 buah jendela pada sisi depan dan masing masing 3 buah di samping kiri dan kanannya. Pintu yang digunakan adalah model pintu panil dari kayu Jati. Pada ruang bawah terdapat dinding yang menutupi ruang tambahan dengan bilah bambu ruang ini biasanya di gunakan untuk tempat ternak dan tempat penyimpanan peralatan nelayan bagi pemiliknya 


\section{Bentuk bangunan type Rumah Semi Permanen di Kelurahan Rangas}

Umumnya type rumah Semi Permanen di Kelurahan Rangas ini denahnya berbentuk segi empat panjang pada dasarnya yang terletak di lantai 1 dengan ukuran panjang biasanyadengan ukuran bangunan panjang 7.5 sampai $8 \mathrm{~m}$ dan lebar 12 meter. Bangunan ini system semi permanen dengan lantai bawah terdapat ruang tamu, runag keluarga dan Dapur biasanya terdapat 1 Kamar tidur,karna terjadi perubahan fungsi ruang pada bagian bawah yang dulunya rumah panggung berubah fungsi kerumah semi permanen, pada lantai 2terdapat ruang untuk kamar tidur dan teras balkon depan rumah yang dulunya teras depan pada rumah panggung. Ukuran teras 1.00 meter x 7.50 samapi 8 meter.tangga berpindah pada area belakang ruang dapur pada lanati bawah rumah Jumlah tangga biasanya berjumlah ganjil, dengan bilangan 5, 7, atau 9. Bentuk rumah semi permanen ini bisanya terdapat penambahan ketinggian pada bagian bawah lantai 01, yang dulunya adalah kolong rumah panggung, ini memiliki ketinggian tiang untuk kolom rumah sekitar $2.00 \mathrm{~m}$ ditambah menjadi 250 sampai 3.00 meter dengan tiang material kayu yang dulunya digunakan pada rumah panggung. Tampak bangunan rumah semi permanen ini layaknya rumah panggung pada bagian atasnya namun terdapat penambahan ruang di bawah jadi modelnya seperti rumah berlantai 02 namun menggunakan material semi permanen pada lt 02, menggunakan material papan kayu pada selubung bangunan dan pada dinding teras depan dengan hiasan ornamen. Menggunakan jendela kaca dengan kusen jendela dan pintu terbuat dari kayu. Ukuran jendela $70 \mathrm{~cm}$ x $110 \mathrm{~cm}$. Terdapat 2 sampai 3 buah jendela pada sisi depan dan masing masing 3 sampai 4 buah di samping kiri dan kanannya. Pada bagian bawah pun juga seperti itu. Pintu yang digunakan adalah model pintu panil dari kayu Jati.

\section{Analisis Tata Letak \& Orientasi Rumah Nelayan dan tata massa Bangunan terhadap tanggap kebencanaan di Kelurahan Rangas, Majene Sulawesi Barat.}

Secara keseluruhan Pola permukiman di Kampung nelayan di Kelurahan Rangas ini cenderung teratur dibeberapa lingkungan, kecederungan pola tak teratur ada terdapat di bagian lingkungan Rangas Barat dan Rangas Timur yang letaknya berada di bagian tepi pesisir, Penduduk biasanya menempati lahan kosong di tepi pesisir, biasanya ketidak teraturan ini Nampak pada lahan yang belum terbetuk pola jalur / akses jalan. Sehingga cenderung polanya organik yang bisanya bertumbuh dan semakin padat kearah laut. Pentingnya orientasi bangunan dan jarak antara rumah yang berdekat dengan laut sesungguhnya sangat perlu dipertimbangkan, namun ada beberapa rumah yang mengabaikan hal tersebut sehingga menimbulkan pola ini tidak tertata dengan baik karna berkembang berdasarkan kebutuhan dan aktivitas penduduk.pada umumnya rumah dibeberapa lingkungan beroreantasi mengikuti pola sirkulasi yang ada, namun sebagian rumah ditepi pantai umumnya menghadap ke laut dengan pola liniear mengikuti bibir pantai. Penangan ini seharusnya dilakukan sejak awal untuk mencegah terjadinya potensi bencana dengan perlunya penataan tata letak bangunan yang adaktif, alternatif yang dapat dilakukan:

1. Bangunan rumah seharusnya berpola teratur yang sedapat mungkin sejajar dengan arah penjalaran gelombang pasang dan Tsunami atau dapat tegak lurus dengan garis pantai agar dapat memberikan ruang dan tekanan air yang relative kecil. 
2. Bangunan disusun dengan pola grid karna hal ini dapat memberi koridor tegak lurus terhadap garis pantai dan jalan lingkungan sebagai aksesnya

3. Bagian lebar pada sisi bangunan dibuat sejajar garis pantai sehingga dapat mengurangi tekanan air dan angina musim yang dapat menerpa bangunan, dengan orientasi laut dan jalur sirkulasi.

4. Lokasi permukiman minimal setback $100 \mathrm{~m}$ atau dengan radius $>200$ meter dari tepi / bibir pantai yang mana adalah zona yang paling rawan terkena gelombang ekstrim

5. Pertimbangan arah angin menentukan orientasi bangunan. Sebaiknya mengurangi bukaan rumah yang letaknya didaerah baris pertama dari laut terutama yang kurang vegetasi untuk mereduksi tekanan angin.

6. Arah orientasi bangunan berkaitan dengan bentuk bangunan, dimana bentuk bangunan akan berpengaruh terhadap tekanan angin, sebaiknya sisi lebar bangunan tegak lurus terhadap arah angin, untuk mengurangi bidang terluas bangunan.

Kepadatan bangunan di kampung nelayan kelurahan Rangas terbilang cukup signifikan dikarenakan wilayah kelurahan ini memiliki populasi penduduk yang sangat tinggi. Lahan yang terbangun di wilayah ini $60 \%$ sampai $70 \%$. Umumnya bangunan dengan jarak antara 1 samapi 3 meter. Bangunannya bercirikan arsitektur rumah panggung sebagai ciri arsitektur tradisional, memiliki bentuk yang adaptif terhadap bencana alam. Namun beberapa rumah panggung telah dikembangkan pada bagian kolong rumahnya, dengan konstruksi pondasi umumnya adalah pondasi umpak dengan tiang kayu yang menumpu bebas pada beton.

Sebagai dasar perencanaan rumah layak huni dan tahan bencana maka sebaiknya pedoman perencanaan rumah layak huni dan tahan bencana diawali dengan tata lingkungan permukiman kemudian bentuk rumah layak huni dan tahan bencana di wilayah ini yang disesuaikan dengan SNI 03-1733-2011, sehingga bentuk hunian dapat disesuaikan dengan kondisi lingkungan pesisir ini. Dari penelitian ini ditemui bahwa penataan bentuk dan massa bangunan rumah pada Kampung Nelayan di Kelurahan Rangas:

1. Kepadatan bangunan di Pulau Saugi cukup tinggi dengan lahan terbangun $60 \%$ $70 \%$, terutama di daerah tepi pantai dengan jarak antar bangunan $\pm 1-3 \mathrm{~m}$, sedangkan jarak antar bangunan di daerah tengah pulau antara $2-5 \mathrm{~m}$.

2. Umumnya bangunan rumah di Pulau Saugi berupa rumah panggung sebagai ciri arsitektur tradisional, memiliki bentuk yang adaptif terhadap bencana alam.

3. Bentuk rumah Rumah panggung telah dikembangkan pada bagian kolong rumahnya, dengan konstruksi pondasi umumnya adalah pondasi umpak dengan tiang kayu yang menumpu bebas pada beton.

4. Penambahan ruang pada kolong bawah rumah menjadi solusi sebagai cara mengatisipasi bencana angin musim namun kurang efektif untuk wilayah pesisir yang rawan terhadap bencana banjir dan masuknya air pasang dari arah laut. 
5. Bahan bangunan yang digunakan pada rumah panggung umumnya menggunakan bahan yang ringan seperti kayu, bambu, seng, dan nipah.

\section{Kesimpulan}

Pada umumnya Typologi Rumah nelayan tanggap bencana di Kelurahan Rangas terdapat tiga kelompok yakni type rumah panggung, type rumah permanen dan type rumah semi permanen. Terdapat beberapa faktor fisik dan non fisik yang mempengaruhi typology rumah nelayan ini, diantaranya adalah fisik bangunan pada rumah panggung, semi permanen dan permanen. Pada rumah terjadi perubahan bentuk rumah dari awalnya rumah panggung menjadi rumah semi permanen yang seluruh area bawahnya difungsikan sebagai ruangan sehingga bentuk rumah panggung berubah menjadi bentuk semi permanen, salah satu penyebab adanya keinginan kenyamann dan keamanan warga terhadap bencana utamanya bencana angin musim yang datang tiap tahunnya. Meski faktor ini bukan hanya untuk penyelesaian bencana yang lainnya. Pada analisis didapat bahwa typology rumah nelayan yang banyak terjadi pada rumah semi permanen Dominan terdapat pada area yang dekat dengan area pesisir dan berada pada sebelah barat dan Timur di Kelurahan Rangas. Namun disisi lain faktor perubahan typology rumah ini sebenarnya bukan satu satunya solusi untuk keamanan dari bencana tetapi terdapat faktor yang lain yang semestinya diperhatikan seperti pengaruh orientasi arah rumah, bentuk dan model atap rumah, penempatan posisi pada area pesisir,dll. Selain itu terdapat faktor non fisik yang didalamnya berpengaruh seperti faktor psikologis, Hukum dan ekonomi dan social budaya masyarakatnya.

Ucapan terimakasih kepada Direktorat Riset dan Pengabdian Masyarakat - Direktorat Jenderal Penguatan Riset dan Pengembangan, 7/E/KPT/2019 tahun 2019 dan LPPM Universitas Sulawesi Barat yang telah membantu dalam pendanaan pada penelitian ini.

\section{Referensi}

1. Zefri, Kajian Tipologi Kawasan Pesisir Untuk Pengembangan Permukiman Nelayan Mensapa Kabupaten Nunukan Perbatan Negara Indonesia Malaysia. Seminar nasional Teknologi,2018.

2. Harley Rizal Lihawa1, Nindyo Suwarno2, Wiendu Nuryanti3, The Achitectural Housing typology A Case Study on Jawa Tondano (Jaton Community in Reksonegoro Village, Gorontalo District.

3. Peraturan Kepala Badan Nasional Penanggulangan Bencana Nomor 10 Tahun 2008 tentang Pedoman Tanggap Darurat Bencana, Badan Nasional Penanggulangan Bencana(BNPD),2008.

4. Mulyati Ahda, Sarwadi.A. Nilai Nilai Lokal pada Tipologi Rumah Tinggal Permukiman Perairan di Sulawesi Tengah, 2013.

5. Aditiansyah Ismawan, Eni Mahawati. Hubungan antara Tingkat Pengetahuan penghuni dan Fasilitas Rumah Susun Terhadap Kesiapan Tanggap Darurat Bencana Kebakaran di Rumah Susun Pekunden Kota Semarang,2014.

6. Kantor Badan Statistik Majene Sulawesi Barat, 2018. Majene Dalam Angka 2018,

7. Kantor Badan Statistik Majene Sulawesi Barat, 2018. Kecamatn BanggaE dalam Angka 2018.

8. Yulia Iriani Lia. Penerapan Teknologi Hasil Litbang Bidang Permukiman Dalam Mendukung Pembangunan Infrastruktur yang berkelanjutan,2018. 
9. Resti Piutanti, Rumah Susun Dengan Aspek Tanggap Lingkungan di Lembong, Brantas, Malang.

10. https://www.pu.go.id/berita/view/12175/menteri-basuki-canangkan-pembangunanrumah-nelayan-berteknologi-risha 